\title{
Percutaneous, minimally invasive approach to implantable left ventricular assist device deactivation
}

\author{
Sumanth Kidambi, MD, Yasuhiro Shudo, MD, PhD, Michael D. Dake, MD, Y. Joseph Woo, MD, and
}

Richard V. Ha, MD

\footnotetext{
From the Department of Cardiothoracic Surgery, Stanford University School of Medicine, Stanford, Calif. Disclosures: Authors have nothing to disclose with regard to commercial support.

Drs Sumanth Kidambi and Yasuhiro Shudo contributed equally to this work.

Received for publication July 10, 2017; revisions received Aug 9, 2017; accepted for publication Aug 28, 2017; available ahead of print Nov 1, 2017.

Address for reprints: Richard V. Ha, MD, Department of Cardiothoracic Surgery, Stanford University School of Medicine, Stanford, CA 94305 (E-mail: richardvha@gmail.com).

J Thorac Cardiovasc Surg 2018;155:653-4

$0022-5223 / \$ 36.00$

Copyright (C 2017 Published by Elsevier Inc. on behalf of The American Association for Thoracic Surgery

https://doi.org/10.1016/j.jtcvs.2017.08.120
}

We previously demonstrated ${ }^{1}$ a successful catheter-based deactivation of a HeartMate II (Thoratec Corporation, Pleasanton, Calif) device that had been placed as a "bridge to recovery" therapy. ${ }^{2}$ In the case illustrated here, we modified and extensively applied this technique to treat recurrent left ventricular assist device drive line infection by deactivating the HeartMate II ventricular assist device in a percutaneous and minimally invasive manner, in which a 22-mm Amplatzer Vascular Plug II (St Jude Medical, St Paul, Minn) was deployed under fluoroscopy through

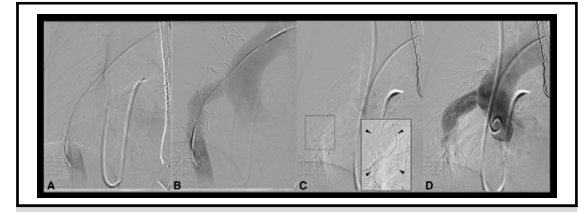

Percutaneous, minimally invasive, catheter-based approach to deactivate HeartMate II VAD.

Central Message
A successful catheter-based deactivation of
HeartMate II ventricular assist device to treat
recurrent drive line infection.

See Editorial Commentary page 655

the right femoral artery in the distal outflow graft $1 \mathrm{~cm}$ proximal to the aortic anastomosis (Figure 1). No Doppler flow was detected either around the plug or inside the left ventricle on transesophageal echocardiography. At 9 months after the deactivation, the patient remains in excellent health without any evidence of infection.

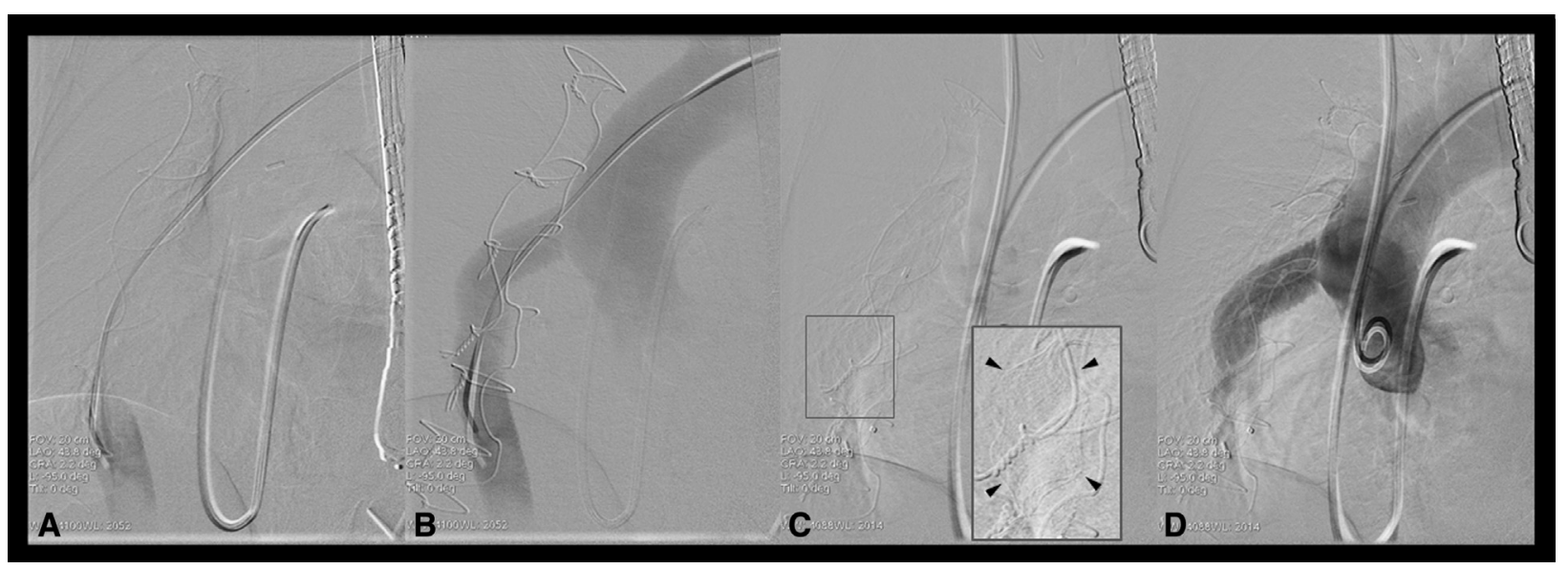

FIGURE 1. A, The outflow graft of the left ventricular assist device (HeartMate II; Thoratec Corporation, Pleasanton, Calif) was accessed under fluoroscopy. B, Aortography showed the location of outflow graft of the left ventricular assist device to the aortic anastomosis. C, A 22-mm Amplatzer Vascular Plug II (St Jude Medical, St Paul, Minn) was deployed under fluoroscopy in the distal outflow graft $1 \mathrm{~cm}$ proximal to the aortic anastomosis. $\mathrm{D}$, Angiography revealed trace retrograde flow of contrast medium through the occluded outflow of the left ventricular assist device. 


\section{References}

1. Zeigler SM, Sheikh AY, Lee PH, Desai J, Banerjee D, Oyer P, et al. A novel, catheter-based approach to left ventricular assist device deactivation after myocardial recovery. Ann Thorac Surg. 2014;98:710-3.
2. Matsumiya G, Monta O, Fukushima N, Sawa Y, Funatsu T, Toda K, et al. Who would be a candidate for bridge to recovery during prolonged mechanical left ventricular support in idiopathic dilated cardiomyopathy? J Thorac Cardiovasc Surg. 2005;130:699-704. 